\title{
Academic-industry partnership framework of Mariano Marcos State University
}

\author{
Robert A. Salvador ${ }^{1}$, Cherrypn B. Barbacena ${ }^{2}$, Francisco D. Esponilla II $^{3}$ \\ ${ }^{1}$ Science in Industrial Technology, Mariano Marcos State University, Philippines \\ ${ }^{2}$ Professional Education Department, Technological University of the Philippines, Philippines \\ ${ }^{3}$ University Research and Development Services, Technological University of the Philippines, Philippines
}

\begin{tabular}{l} 
Article Info \\
\hline Article history: \\
Received Dec 1, 2020 \\
Revised Aug 9, 2021 \\
Accepted Sep 9, 2021 \\
\hline
\end{tabular}

Keywords:

AIP framework

Development

Grounded-theory

Linkages

Triangulation

\begin{abstract}
Higher education is a window for people to gain knowledge and skills. People who step out in higher academic learning are expected to be equipped with competencies needed in the different job sites. Therefore, the responsibility of every institution to seek alternatives to further enhance academic opportunities. The main objective of this study was to develop an academic-industry partnership (AIP) framework for the Mariano Marcos State University (MMSU). A qualitative research design was utilized in exploring the partnership engagement of the different colleges of the university. Interviews inquiring about participants' lived experiences were purposively selected for a grounded-theory analysis following the thematic coding process. The coding was further subjected to a triangulation for purposes of validating the data from various sources. The study revealed that the AIP is focused on the areas of instruction, research and production, and research and extension. This leads to the creation of the AIP framework which can contribute to the development of AIP policy of the MMSU and other higher education institutions.
\end{abstract}

This is an open access article under the CC BY-SA license.

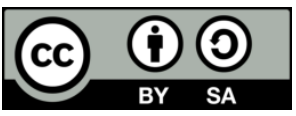

\section{Corresponding Author:}

Francisco D. Esponilla II

University Research and Development Services

Technological University of the Philippines

Ayala Boulevard, Emerita, Metro Manila 1000, Philippines

Email: francisco_esponilla@edu.ph

\section{INTRODUCTION}

Academic-industry partnership (AIP) has been a significant contributing factor in identifying the right education, skills, and attitude towards matching graduate employment competencies available in the job market [1], [2]. In fact, industry partnership is one of the success indicators set by the Commission on Higher Education (CHED) - the Philippine Higher Education Institutions (HEIs) [3]. Likewise, it is one of the university's accreditation requirements of the Accrediting Agency of Chartered Colleges and Universities in the Philippines (AACUP). Over the years, the Mariano Marcos State University (MMSU) is developing a strategic plan to enhance and capacitate its AIP engagement. To date, only a few AIP anchored goals in the Philippine HEIs were recorded which is not enough to sustain the target required of the Higher Education Authorities [4], [5]. It is for this reason that the current study is aimed at exploring the AIP engagement of various colleges in the university and benchmark with other State Universities (SUCs) and HEIs academic institutions. The results of this study provide an important contribution to: i) The programs of the university because the findings can be utilized as bases for realignment and reconciliation of AIP goals and objectives of both partners. Thus, achieving the university's target particularly in the linkages where AIP is evaluated as 
a university quality management objective. Along with other academic institutions, the results would help to find out whether the strategies and approaches employed in AIP engagement are responsive to the current industry set up; ii) The university because the data generated can be laid as foundation of a comprehensive AIP engagement; iii) The students because of the penultimate exposure and opportunities to industry partners through immersion and academic support system; iv) The industry partners because of the intensified AIP arrangement and other privileges that can be derived from partnership engagement; $v$ ) The education experts who integrates specific necessary skills, right attitude, and proper education in the curriculum; and vi) The students who equip themselves of the industrial competencies for employment preparation.

By virtue of the Presidential Decree No. 1279 signed by then President Ferdinand E. Marcos, the Mariano Marcos State University was established on January 6, 1978. The decree resulted in the merging of Mariano Marcos Memorial College of Science and Technology (MMMCST) in Batac with the Ilocos Norte College of Arts and Trades (INCAT), Northern Luzon State College (NLSC) in Laoag City, and integrated the college departments of the Ilocos Norte Agricultural College (INAC).

The realization of AIP goals and objectives is a manifestation of rationalized commitment in implementing programs and policies that would enhance university-based curriculum appropriate for work placement [6]. Adequate facilities, competent human resources, responsive curriculum, admission and retention policy and fluid AIP are dynamic forces towards academic excellence. Understanding systems employed is an imperative undertaking for it will provide explicit evidence whether these systems are efficient or not.

The Commission on Higher Education (CHED) having the highest authority to look after the national State Universities and Colleges (SUCs) of the country, has been coordinating with the various HEIs and industries to address academic industry mismatch. Human resource requirements have been articulated in industry road maps and strengthening partnership with private industries and companies for the enhancement of the knowledge, skills and attitudes of graduates which are necessary in the preparation for employment [1], [7]. Indeed, HEIs are expected to carry out their respective mission, goals, and objectives. The delivery of core functions is driving every institution to find technology advancement and academic possibilities that could be found outside their domains. The AIP evidently exists in almost every institution particularly SUC's because it is a contributor of support system and opportunities.

Despite the significant results of studies on AIP, HEIs are still experiencing difficulties in partnership engagement. Traditionally, AIP engagement was done within the area where the academic institutions are located. Benchmarking is also done through the word of mouth by employed graduate students and the industries nearby. The absence of a thorough research, proper monitoring, records of curriculum revision are not supportive by an extensive study. The current research purposively consolidates models which were used by the interviewed experts from other academic institutions. Theoretical models utilized in the literature are also presented to evaluate partnership engagement of the institution under study.

\section{LITERATURE REVIEW}

Literatures have explained that academic-industry partnership (AIP) engagement may have performed and reached a particular point in the engagement [8], it was found out that some areas of AIP engagement has yet to maximize its optimum purpose. AIP has also been studied as one of the aspects of open innovation, where industries rely on the scientific research outside their boundaries to achieve results [9]. Also, AIP engagements are recognized for providing a new way of academic and industry collaboration. However, there is limited research investigating its impact on school-to-work transitions [8]. Even information from social media is not even enough to provide indicators for innovating AIP [10]. King and Persily [11] believed that researchers' different methodologies, research agenda, and publications options also limits AIP awareness. They suggested that academic institutions should work with the industry or vice versa in order to come up with a two-part solution in identifying the needs of the industry [11].

The study of Flynn, Pillay and Watters [8] supports that AIP is a way of providing an avenue for employment opportunities. Their study utilized the Boundary Crossing Model (BCM) of Akkerman and Bakkers [12], where it identified three major stages of honing AIP. The first stage of the BCM is identification. This is the process of understanding the differences between the organizations human resource and industry such as the sources of operational differences and commonalities, funding sources, roles and responsibility of each partner, skills and training needs, and risks assessments. The next stage is coordination that is the most effective communication channel between academic and industry partners. This stage involved identifying academe and industry individual roles and responsibility in addressing potential risks that threaten the sustainability of the AIP. Next to the identification stage is coordination. According to Cash, et al. [13], coordination between schools and industry is critical to effectively operationalizing AIPs. Cash, et al. [13] explained that coordination is a crucial tool of crossing the barriers between two parties. The third 
stage is reflection. It is a mechanism which reflects upon the operations best practices and learning about the new and emerging practices [12].

The study of Sannö, et al. [14] found out that the universities tried to increase their interaction with the industry, however, their AIP is under pressure due to some factors, skills and awareness to meet different expectations. This is influenced by various collaboration activities. Trust is in interpersonal skills, the ability to envision targets, and communication skills according to Safrit [15] are factors of successful solution to barriers of partnership. For an improved collaboration engagement with the private sectors, one should consider several factors [16]. The difference in partnership goals and objectives, geographical conditions, implementation and monitoring policy and industry setting. Brunell, D'Este, and Salter [16] in their investigation with the factors that diminish the barriers to university-industry collaboration found that collaboration, breath of interaction, and organization trust lower the barriers towards industry collaboration. Understanding these factors could help university-industry (UI) to develop an AIP policy. The study of Bernarte [17], suggested that a university function should not be confined within its core function of instruction, research and extension but should harmonize with a broader external boundary. For him, though academic institutions and industry are operating with differentiated purposes of educating and business respectively, the growing complexity in industrial advancement and various AIP linkages brings closer to work together for a cause of providing skilled human resources.

In the Philippines, as mentioned by Bernarte [17], academic-industry partnership has been advocated by higher education institutions for the past years in consideration with a large enrolment, under investment and poor output quality, and mismatch of the curriculum skills integration. Bernarte [17] further mentioned that AIP is not a new concept. In fact, various AIP were initiated during the 90's. And from this AIP experience, partnership models have been developed and introduced. This study utilized a mixed-method approach of research and tried to find out which among the HEI's in NCR-ZRC are involved in AIP. It is clear in their findings that the top 3 benefits gained by HEI's in AIP engagement are student training, Job placement of graduates and curriculum development. Moreover, problems in AIP engagement were also identified in this study. Coordination is the major problem of HEI's followed by financial resources and structure and policies.

The study of Safrit [15] about the successful AIP also found out the different barriers of partnership. Researcher utilized a qualitative investigation design under grounded theory method. Researcher focused on the characteristics of a successful AIP. There were 57 key informants of the study that identified the factors to successful partnership, such as intellectual property rights, agreements, technology transfer, defined goals, objectives and targets, human resources, internal and external issues, and academic freedom [15].

One of the curricular initiatives to further enhance delivery of academic necessities as mentioned in the previous discussions is the AIP, which includes; immersion, internship, and on-the-job training, resources sharing, technology transfer, funding and other support systems. However, such partnership often ends or is limited only to deployment and acceptance of on-the-job trainees due to unidentified issues. It is in this case that a vital role of the industry is necessary. Working with the industry will help identify successful indicators for curriculum integration that would potentially raise capacity of increasing employment opportunities of the graduates. Knowing that industries are the providers are service oriented and focused on employment, Go, et al. [18] stated that the industrial sector plays an important role towards economic development. According to Sair and Danish [19], industrial advancement improves product quality and increased marketability. Industrialized countries have a stronger resilience and are more capable against developmental aggression. Labor industry creates a larger scope of skills enhancement, training, and technology orientation; thus, create jobs.

As the researchers read the literature and previous studies, they came to find out that motivation of both partners is one of the many issues to be addressed and obviously stated as the major concern in AIP engagement. It was clearly stated in the study of Guimon [20], the need to reconcile indifferences is one way to address the issue. The researchers found this to be an important factor in the implementation of AIP and it serves as a theoretical basis for the development of the first and second objective of this study. The need to know one's goal is an initial step to understand his existence.

Educating people is the role of Higher Education (HEs). To be sustainable socially developed, the HEIs should be the focal point in industry partnership. An integrated curriculum-based industry pacedfocused skills and development would help improve innovation practices. HEIs are the key drivers of economic development and competitiveness [21]. Education provides an individual competitive advantage. Aside from being embedded in the curricula, HEIs offer professional training to promote lifelong learning and professional growth and development [21].

Universities can revise their curriculum so that they remain abreast to the technological changes. International labor market data and analysis of various jobs and skills is made now accessible. It is where the trend of the current employment system relied. A strengthened AIP promotes the acquisition of skills and 
knowledge and makes sense employment qualifications. Bentley [22] suggested that a continued AIP paved the way of sustaining collaboration with industries in facing the challenges of ever-changing business needs. While leveraging graduates with the appropriate characteristics for employment productivity.

Because of the substantial and beneficial results of the growing literature digested. The researchers were motivated to conduct this study with the main purpose of exploring the AIP engagement experiences of Mariano Marcos State University (MMSU) and develop an understanding that will serve as basis for the development of AIP framework for the university. As it has been discussed earlier, the AIP is undergoing different concerns and difficulties as regards implementation of programs. This study aimed to generate information directly from the people who have experiences in the AIP engagement of the university.

\section{RESEARCH METHOD}

This study utilized qualitative research that is exploratory in nature. It intends to explore and not to predict the outcome of the academic-industry partnership (AIP) engagement of Mariano Marcos State University (MMSU). Furthermore, this will also be used to explore the meaning and understand the complexity of partnership environments, like the nature of people's experiences. The current study further intends to understand the goals and objectives of the partnership engagement to describe how strategies or approaches were implemented and discover the extent of achievement based on the data gathered from the AIP experts who served as the participants of the current study. A traditional way of developing strategic approach of assessing the university's AIP is being challenged by this new research that it intends to conduct an extensive approach of integrating AIP practices that other academic intuitions are strong in the area particularly the role of the industry as academic stakeholder in developing students' holistic competence.

As mentioned in the previous literature, qualitative research can use multiple systems of inquiry. One of which is grounded theory where the researcher decided to adopt since the objective of this study is to explore AIP engagement of MMSU and will not try to give conclusion to such but rather to find new theories by examining concepts grounded in the data. Thus, researchers used grounded theory as means of inquiry. The study employed the grounded theory-based inquiry to develop the basic social process and structures that influence academic-partnership [23]-[25]. According to Strauss and Corbin [26], in a grounded theory the participants tell their own stories, while the investigators narrate, transcribes, and interprets the stories to build an articulate understanding about it. Because of the nature and scope of this study, the researchers bank on the interpretive/constructivist paradigm of research as a supporting philosophy in conducting the phase I of this study as seen in Figure 1.

Interpretivist/constructivist research understands the world of human experience [27]. Previous studies [28], [29] asserted that interpretivists discover phenomena through participant's views, own background, and experiences. It is an exploratory process involving individual personal experiences [30]. Since interpretivist believed that there is no single reality or truth, in this study as seen in the interpretivist paradigm as shown in Figure 1, individual responses of the participants are treated equally important to come up with consistent data interpretation [31]. It is also where the basis that the data are subjected to a grounded theory analysis.

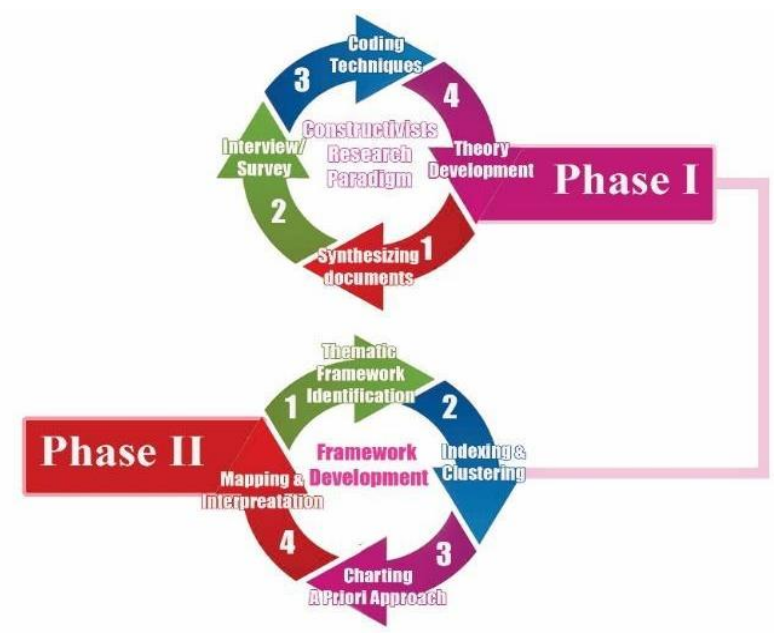

Figure 1. Stages of phase I and II 
The results of the grounded theory methodology in this study were utilized as the basis for the development of an AIP framework for MMSU and other Philippine higher education institution (HEIs). Figure 2 illustrates the research procedure that was undertaken. It also provides specific activities in conducting the research.

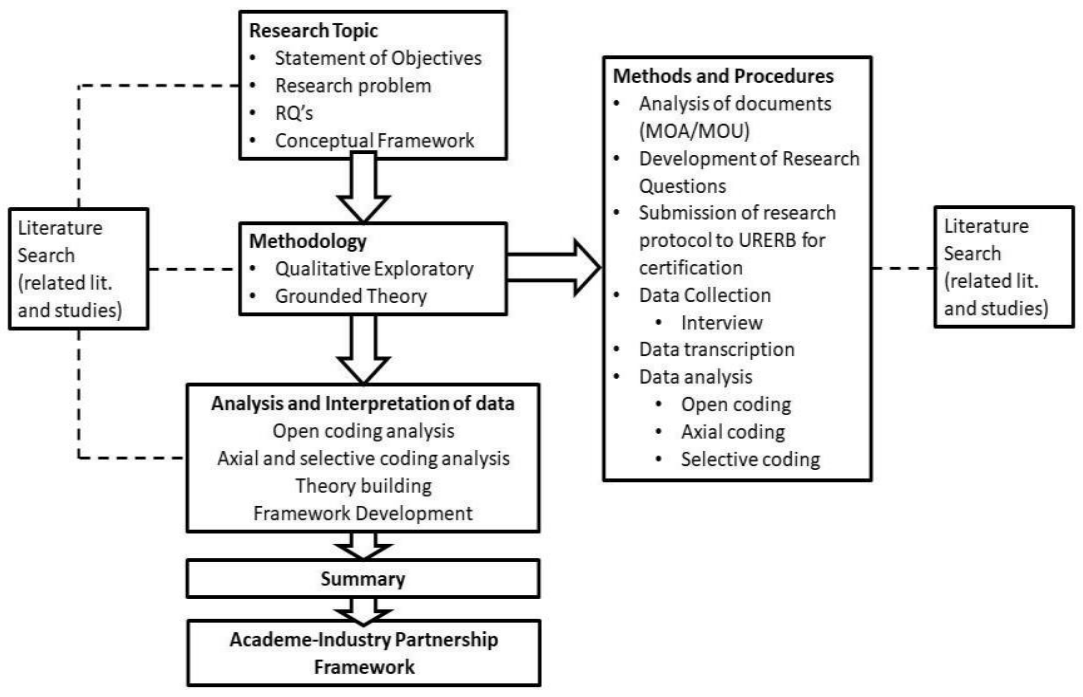

Figure 2. The research processes

The first step in the research process is the conceptualization of research topics. The conceptualization process includes the development of objectives and research questions. Such questions and objectives are the result of synthesizing the documents provided by the respondents. Conceptual framework was also developed in this stage of the research process. It is important to note that this stage and the process involved were guided by literature and related studies. In the methodology stage, this study utilized qualitative exploratory research. The literature and related studies provided the basis for the researcher to adapt the grounded theory methodology. Analysis and interpretation of data were also conducted using the appropriate coding techniques as a requisite of the methodology used. The result of the coding techniques provides a basis for the emergence of concepts and theories which were utilized in the development of the AIP framework for Mariano Marcos State University.

The purposive sampling was utilized in this study because the people involved from the academe will be specifically picked as respondent because of their direct involvement in the AIP engagement. This will provide multiple dimensions and different perspectives concerning partnership involvement. The researchers continue to add individuals to the sample until theoretical saturation is reached; that is, when the complete range of constructs that make up the theory is fully represented by the data. Although it is impossible to predict what sample size will saturate a given theory [32].

The main instrument of this research study is a semi-structured survey questionnaire as an interview guide. This study adopted Rubin and Rubin [33] on the formulation of survey questions and conducts followup to discover new ideas, encourage detailed elaborations, and ascertain completeness of the story. The researchers formulated research questions that will draw information related to the objectives of this study. Such a question may also have a follow up question to drive the respondent to disclose and will elaborate further their experiences [34]. Data was subjected to coding for thematic organization. While triangulation techniques were employed to verify and confirm the responses from a variety of sources to document themes which include the interview results, literatures studies, and documents relative to the participants specialization and study.

\section{RESULTS AND DISCUSSION}

Data gathered provides imperative explanations and connections to the theories, because as it has been mentioned by Strauss and Corbin [26] that theories cannot be built with actual incidents, events and happenings are taken as, or analyzed as, potential indicators of phenomena, which are thereby given conceptual labels. Figures with discussion are described in this section to clarify strategic frameworks for 
instruction, research, extension, production, and community partnership. Likewise, a framework for academic-industry partnership (AIP) is presented to summarize the knowledge requirements identified based from the study findings and the related literatures employed in the current study.

\subsection{Academic-industry partnership through instruction}

Figure 3 is an illustration on how the concepts that emerged in this study were utilized in the development of the proposed AIP framework. The primary consideration in the TED triangle are the people involved in the partnership engagement. Recruitment of people is an initial step in the process, and it is very important. The selection of people that will be handling the specific task must possess the right knowledge and attitude towards the job. Recruitment procedures and policies must therefore be given attention. In the discussion of Anderson [35] in a journal published by Forbes, she mentioned that putting the right person in the right seat has always been significant in the success of the company. Thus, placement is consequently an imperative step in the process.

The next concept is focused on retention. Retention on the other hand according to Halim, et al. [36] will sustain individuals' knowledge, lessen cost of employment replacement, and maintain competitive advantage which reflects the industry or the company's productivity. Turnover in this case is not referring to employees leaving in the university but rather the rotation or changing the assignments of the personnel involved in the partnership engagement. One of the causes of turnover in partnership engagement is that the personnel has also other designations or assignments aside from teaching. It is then the reason for some to leave the partnership engagement and being replaced by a new one. This concern is found to be a factor in the implementation of the partnership engagement.

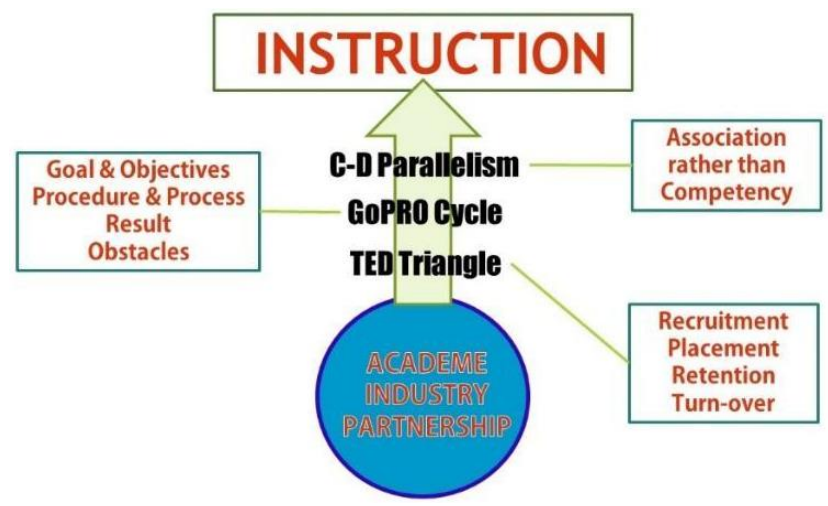

Figure 3. AIP through instruction

It is very important to note that setting the goals and objectives of partnership engagement is the first thing to do. This is because it leads to the direction of the partnership engagement. As it has been mentioned in the previous discussions in this study, goals and objectives are the general guidelines that explain what the company would want to achieve.

The procedures and processes in the partnership engagement are the ingredients in the achievement of the goals and objectives. It where the strategies and approaches are employed. The competence of the people involved in the partnership are being tested in this stage, their capability to make decisions and judgements will be seen. The results are the definition of the strategies and approaches being used in the process. The outcomes are upshot of actions and measures being implemented along the process. The results would also be the basis in determining the obstacles in the process.

Obstacles are the ones preventing you from achieving something. They are the ones making the process to slow down or to make the procedures complicated. In this case, the partnership engagement procedures must be evaluated. Listing the situations and actions that hamper the partnership engagement are vital in setting the next goals and objectives. This will provide anticipatory measure to avoid or correct such problems in the previous partnership engagement.

The C-D parallelism is the result of the data analysis being done which provides psychological considerations in partnership. The letter " $\mathrm{C}$ " stands for commonalities which literally mean that both partners have something in common while letter " $D$ " stands for difference. Identifying the commonalities between partners will lead to association while determining the differences is leading to comparison. 
Association denotes cooperation while comparison signifies competition. Partnership on the other must benefit both partners. In this case, rather than determining differences, identification of commonalities must be the primary consideration. Cooperation will generate mutual benefit along with equal opportunities and privileges and competition will cause stand-alone performances and individual benefits. Partnership must benefit both partners and will also cause each other evenly. No party shall be in advantage nor deprived.

\subsection{The connection between instruction and research and production}

Figure 4 provides an overview of how instruction can open opportunities to partner with industry in research undertakings. The existing partnership engagements that are connected in instruction will be utilized to expand partnership in research. If the people involved from the academe were able to present the benefits of research to the industry partners, there might be the chance this industry will be supporting research undertaking. Among the initial research that could be done in relation to instruction are Human Resource Management, Human Resource Development and Curriculum Development. If the cooperating industries will be given sufficient and justifiable reasons, the chances to expand research in the development of products, goods, and services through Research and Development (R\&D). These products, goods and services generated through R\&D's will also provide avenues to revenue generations through commercialization. This will fall into "production" which is also one of the thrusts of the university. In this case, partnership will be strengthened in this area.

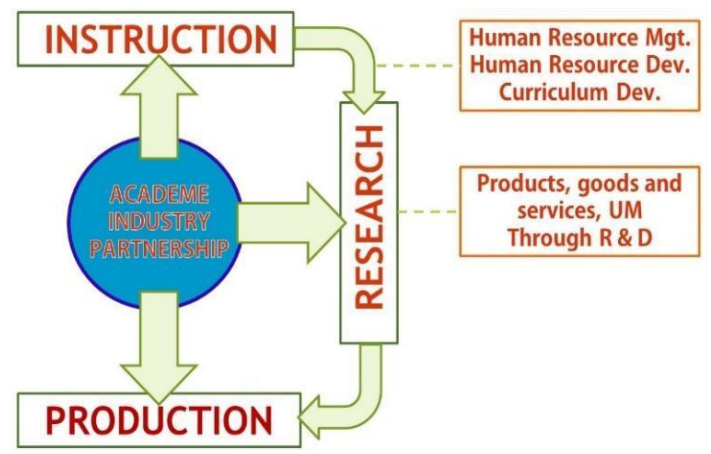

Figure 4. Instruction, research and production

\subsection{Instruction and research as gateway to partnership in extension}

Figure 5 shows how instruction and research provide opportunities for expanding AIP in extension. Extension is one of the four functions of the university. Through instruction and research, the expansion of partnership in extension is the technology transfer through community outreach programs. The research outputs will also benefit the community through commercialization. The industries are also engaging themselves in such programs like extension programs of the university. The people involved in the partnership engagement must be assertive and optimistic in expanding the partnership.

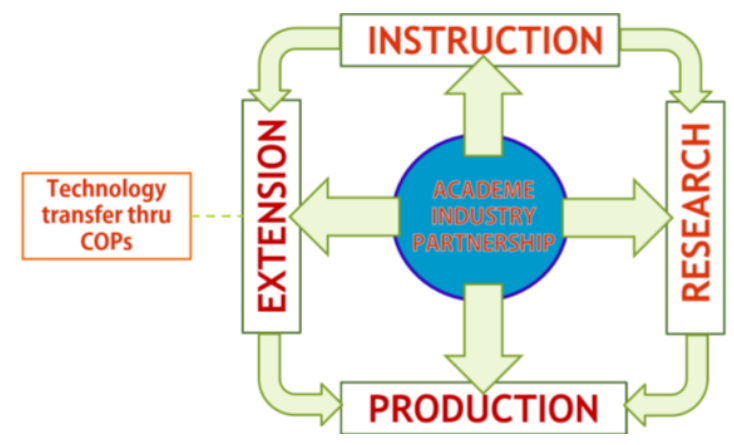

Figure 5. Instruction, research and extension 


\subsection{The academic-industry partnership framework}

The proposed framework shown in Figure 6 is intended primarily to become the basis in undertaking the future partnership engagement. The proposed framework also illustrates the methodologies and procedures that need to be done in the partnership engagement. Furthermore, the proposed framework also provides alternative avenues to reconcile arising problems along the partnership engagement process.

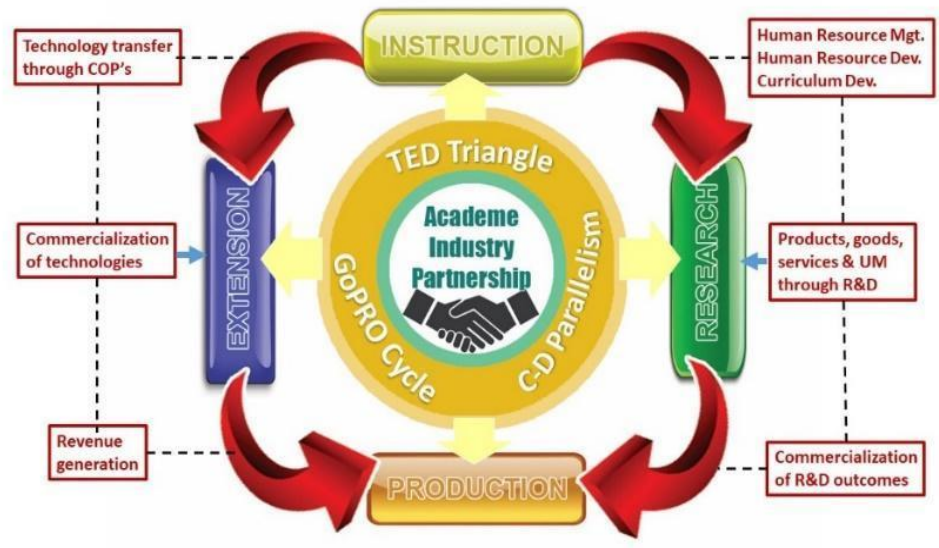

Figure 6. Academic-industry partnership framework

There are four thrusts of the university namely: instruction; research; extension and production. If most of the partnership engagements are related to instruction. It is therefore imperative to choose instruction as an avenue for the partnership in research, extension, or production.

The three concepts that emerged in the study have been introduced in the framework because it is found to be a key factor in the improvement of the implementation of the partnership engagement as it has been singularly discussed in the previous sections.

As it has been mentioned, if industries will be encouraged to participate in research (i.e., human resource management \& development, curriculum development) and if sufficient justification of the benefits will be presented to them, this might open opportunities to further engage in research. In other words, participative research involving the industry might as well provide a steppingstone for the generation of new technologies, techniques and modalities both in the academe and industry. This will also be a breakthrough to the commercialization of products being developed in R\&D methodologies.

In relation to extension, the academe needs to be engaged in this endeavor. This is one of the mandates of the institution of higher learning. This necessity is indeed a criterion in the evaluation of programs in the university. While on the other hand, the industries operate its own extension programs in the community. As it has been mentioned in the background in the study that for a long time the academe and the industry are working in separate domains for time. And this concern shall also be given attention.

In the proposed framework, the well-established partnership in instruction will serve as a window to an opportunity in encouraging the industry partners to engage in extension programs. The academe must therefore be the driver of initiatives and ingenuities that will catch the interest of industry partners to be in the extension programs. In the framework, other than instruction the three concepts could also be employed directly in the partnership engagement of other thrusts. These concepts are not only limited to instruction, but it shall be the initial considerations in the partnership engagement.

\section{CONCLUSION}

Overall, the researcher concluded that the academic-industry partnership (AIP) framework of the university should be standardized base on the higher education authority's generic framework. Experts lived experiences and the cited literature of the research found to have significant contribution to the development of the MMSU's AIP framework. However, the researchers found out that difficulty is within the implementation of the partnership engagement. It is understood based on the underlying meaning of the lived experiences of the participants that there are still extra works to be done to strengthen the faculty engagement, management engagement, and integrate AIP not only in the areas of community-extension partnership, but also in the trifocal functions such as instruction, research, and production. 
The proposed framework of the current study would be of help to strengthen industry partnership by other State Universities in the Philippines. This study also recommends that the proposed AIP framework will be evaluated and validated in a separate study because the researchers acknowledged that every academic institution have different success strategy frameworks.

\section{ACKNOWLEDGEMENTS}

This research work is in collaboration with the research partners from the faculty members of the College of Industrial Education of the Technological University of the Philippines. It is also in grateful appreciation to the expert informants from various MMSU branches that made the result of the study of benefit to the curriculum makers of various HEIs and researchers conducting the same or related studies.

\section{REFERENCES}

[1] R. Pinheiro, P. V. Langa, and A. Pausits, "One and two equals three? The third mission of higher education institutions," European Journal of High Education, vol. 5, no. 3, pp. 233-249, 2015, doi: 10.1080/21568235.2015.1044552.

[2] M. W. Pang, C. H. Leung, and J. Coombes, "Competencies for fresh graduates' success at work: Perspectives of employers," Industry and Higher Education, vol. 33, no. 1, pp. 55-65, Aug. 2018, doi: $10.1177 / 0950422218792333$.

[3] M.T. Montemayor, "University-industry links key to economic growth: CHED chief," The Philippine News Agency, 2019. [Online]. Available: https://www.pna.gov.ph/articles/1063955.

[4] R. E. Rotoras, "Framework for Academe-Industry Linkages: University of Science and Technology of Southern Philippines (USTP)," Philippine Association of State Universities and Colleges, 2017. [Online]. Available: http://industry.gov.ph/wp-content/uploads/2017/05/A-New-Framework-for-Academe-Industry-Linkages-

University-of-Science-Technology-of-Southern-Philippines-by-Dr-Ricardo-Rotoras.pdf.

[5] M. C. Torrentira Jr., "Dimensions of Sustainable Research Collaborations in Philippine Universities," Journal of Public Administration and Governance, vol. 9, no. 2, pp. 17-29, 2019. [Online]. Available: https://ideas.repec.org/a/mth/jpag88/v9y2019i2p17-29.html.

[6] J. S. Jonbekova, M. Hartley, and G. Kuchumova, "Development of university-industry partnerships in Kazakhstan: Innovation under constraint," International Journal of Educational Development, vol. 79, pp. 1-10, Nov. 2020, doi: 10.1016/j.ijedudev.2020.102291.

[7] C. B. Celarta and F. D. Esponilla II, "Industrial education competencies: Valuing students stakeholder's role in the academe," Cypriot Journal of Educational Sciences, vol. 16, no. 1, pp. 46-56, Feb. 2021, doi: 10.18844/cjes.v16i1.5507.

[8] M. C. Flynn, H. Pillay, and J. Watters, "Industry-school partnerships: boundary crossing to enable school to work transitions," Journal of Education and Work, vol. 29, no. 3, pp. 309-331, 2014, doi: 10.1080/13639080.2014.934789.

[9] B. Hou, J. Hong, Q. Chen, X. Shi, and Y. Zhou, "Do academia-industry R\&D collaborations necessarily facilitate industrial innovation in China? The role of technology transfer institutions," Eur. J. Innov. Manag., vol. 22, no. 5, pp. 717-746, 2019, doi: 10.1108/EJIM-09-2018-0195.

[10] B. R. Jasny, et al., "Fostering reproducibility in industry-academia research," Science, vol. 357, no. 6353, pp. 759761, 2017, doi: 10.1126/science.aan4906.

[11] G. King and N. Persily, "A New Model for Industry-Academic Partnerships," American Political Science Association, vol. 53, no. 4, pp. 703-709, 2019, doi: 10.1017/S1049096519001021.

[12] S. F. Akkerman and A. Bakker, "Crossing Boundaries Between School and Work During Apprenticeships," Vocat. Learn., vol. 5, pp. 153-173, 2012, doi: 10.1007/s12186-011-9073-6.

[13] D. W. Cash, et al., "Scale and Cross-Scale Dynamics: Governance and Information in a Multilevel World," Ecol. Soc., vol. 11, no. 2, pp. 1-12, 2006. [Online]. Available: http://www.ecologyandsociety.org/vol11/iss2/art8.

[14] A. Sannö, A. E. Öberg, E. Flores-Garcia, and M. Jackson, "Increasing the Impact of Industry-Academia Collaboration through Co-Production," Technology Innovation Management Review, vol. 9, no. 4, pp. 37-47, 2019, doi: 10.22215/timreview/1232.

[15] L. S. Safrit, "The intersection of academia and industry: Avoiding pitfalls and navigating successful partnerships," Dissertation, University of North Carolina, Chapel Hill, 2014.

[16] J. Bruneel, P. D'Este, and A. Salter, "Investigating the factors that diminish the barriers to university-industry collaboration," Res. Policy, vol. 39, no. 7, pp. 858-868, 2010, doi: 10.1016/j.respol.2010.03.006.

[17] R. P. Bernarte, "Academe -Industry Partnership in the Philippine: Nature, Benefits and Problems," Asia Pacific High. Educ. Res. J., vol. 1, no. 1, pp. 1-34, 2014

[18] D. J. Go, M. A. Promentilla, K. Aviso, and K. D. Yu, "The Evolution of the Key Sectors in the Philippine Economy Using an AHP-Based Sector Prioritization Index," Economies, vol. 7, no. 3, pp. 1-20, 2019, doi: 10.3390/economies7030078.

[19] S. A. Sair and R. Q. Danish, "Effect of performance expectancy and effort expectancy on the mobile commerce adoption intention through personal innovativeness among Pakistani consumers," Pakistan Journal of Commerce and Social Sciences, vol. 12, no. 2, pp. 501-520, 2018. 
[20] J. Guimón, "Promoting University-Industry Collaboration in Developing Countries," The Innovation Policy Platform, pp. 1-11, 2013.

[21] M. Chankseliani, I. Qoraboyev, and D. Gimranova, "Higher Education Contributing to Local, National, and Global Development: New Empirical and Conceptual Insights," Higher Education, vol. 8, no. 1, pp. 109-127, 2021, doi: 10.1007/s10734-020-00565-8.

[22] S. J. Mgaiwa, "Fostering Graduate Employability: Rethinking Tanzania's University Practices," SAGE Open, vol. 11, no. 2, pp. 1-14, 2021, doi: 10.1177/21582440211006709.

[23] D. A. Snow, "Extending and Broadening Blumer's Conceptualization of Symbolic Interactionism," Symbolic Interaction, vol. 24, no. 3, pp. 367-377, 2001, doi: 10.1525/si.2001.24.3.367.

[24] B. G. Glaser and A. L. Strauss, Discovery of grounded theory: Strategies for qualitative research. Routledge, 2017.

[25] M. Birks, K. Hoare, and J. Mills, "Grounded Theory: The FAQs," International Journal of Qualitative Methods, vol. 18, pp. 1-7, 2019, doi: 10.1177/1609406919882535.

[26] A. Strauss and J. Corbin, "Grounded theory methodology, an overview," in Handbook of qualitative research. Sage Publications, 1994.

[27] L. Cohen, L. Manion, K. Morrison, L. Cohen, L. Manion, and K. Morrison, "The ethics of educational and social research," in Research Methods in Education. Routledge, 2018.

[28] J. W. Creswell, Research design: Qualitative quantitative and mixed methods approaches. Sage Publications, 2003.

[29] D. Yanow and P. Schwartz-Shea, "Interpretive Research: Characteristics and Criteria," Revue Internationale de Psychosociologie, vol. 15, no. 35, pp. 29-38, 2021, 2009, doi: 10.3917/rips.035.0029.

[30] N. C. Thanh, T. Thi, and L. Thanh, "The Interconnection between Interpretivist Paradigm and Qualitative Methods in Education," American Journal of Educational Science, vol. 1, no. 2, pp. 24-27, 2015.

[31] S. Patel, "The Research Paradigm - Methodology, Epistemology and Ontology - Explained in Simple Language," 2015. [Online]. Available: http://salmapatel.co.uk/academia/the-research-paradigm-methodology-epistemologyand-ontology-explained-in-simple-language.

[32] J. M. Morse, "Determining Sample Size," Qualitative Health Research, vol. 10, no. 1, pp. 3-5, 2000, doi: $10.1177 / 104973200129118183$

[33] H. Rubin and I. Rubin, "Structuring the Interview," in Qualitative Interviewing (2nd ed.): The Art of Hearing Data. Sage Publication, 2012.

[34] M. Vollstedt and S. Rezat, An Introduction to Grounded Theory with a Special Focus on Axial Coding and the Coding Paradigm. Compendium for Early Career Researchers in Mathematics Education, 2019.

[35] A. R. Anderson, Successful Companies Put the Right People in The Right Jobs. Forbes Magazine, 2013.

[36] Z. Halim, M. M. Waqas, C. A. Edwin, and A. Shah, "Identifying factors for employee retention using computational techniques: an approach to assist the decision-making process," SN Applied Sciences, vol. 2, pp. 1-20, 2020, doi: 10.1007/s42452-020-03415-5. 